\title{
Busca por capitais no campo da escola e sua relação com o desenvolvimento profissional docente de professores supervisores de estágio de Ciências e Biologia
}

\author{
Search for capital in the field of school and its relationship \\ with the professional development of supervisor-teachers \\ of Science and Biology internships
}

\author{
Ana Cecília Romano de Mello ${ }^{1}$ \\ https://orcid.org/0000-0001-7369-0020

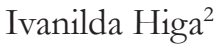 \\ https://orcid.org/0000-0002-7277-3198
}

\begin{abstract}
Resumo: Estudou-se a relação entre o Desenvolvimento Profissional Docente - possibilitado pela supervisão de estágio da licenciatura em Ciências Biológicas - e a busca, por parte de professores da Educação Básica, por capitais no campo da escola. O estudo é de natureza qualitativa e foi desenvolvido a partir de entrevistas semiestruturadas com cinco professores da rede estadual de ensino. Identificados os aspectos de DPD, perceberam-se mobilizações desses professores por diferentes capitais, relacionados com seus objetivos enquanto docentes e com sua trajetória pessoal e profissional. Evidenciou-se uma relação de poder simbólico entre universidade e escola na relação com a produção e apropriação de conhecimento. Espera-se que ao se evidenciar essas relações internas e entre os campos seja possível compreender a complexidade que envolve o estágio supervisionado e se busque valorizar e propiciar a produção de conhecimento também pelos professores da escola e por relações menos hierárquicas entre as instituições.
\end{abstract}

Palavras-Chave: Estágio supervisionado. Formação de professores. Ensino de biologia.

\begin{abstract}
The relation between the Teacher's Professional Development was studied - what is possible through the supervision of interns of teaching in Biological Sciences - and the teacher's search for capital in the field of school. Of qualitative nature, the study was developed from semi-structured interviews with five teachers from state education. Once the aspects of TPD were identified, these teachers were mobilized for different scenarios, related to their objectives as teachers and with their personal and professional trajectories. A relation of symbolic power between university and school in the relation with production and appropriation of knowledge was evidenced. It is expected that by highlighting these internal relations and between fields it is possible to understand the complexity that surrounds the supervised internship and seeks to value and promote the production of knowledge also by the school teachers and perhaps less the hierarchical relations between university and school.
\end{abstract}

Keywords: Supervised internship. Teachers' education. Biology teaching.

\footnotetext{
${ }^{1}$ Universidade Federal do Paraná (UFPR), Programa de Pós-Graduação em Educação, Curitiba, PR, Brasil. E-mail:<ana.mello@ufpr.br>.

${ }^{2}$ UFPR, Departamento de Teoria e Prática de Ensino, Programa de Pós-Graduação em Educação, Curitiba, PR, Brasil.
} 


\section{Introdução}

No Brasil, desde o século XIX com o Ensino Normal, vem sendo desenvolvida uma relação entre as instituições reconhecidas como formadoras de professores (atualmente as Instituições de Ensino Superior) e as instituições de Educação Básica (PIMENTA, 2006; SAVIANI, 2009). Essa relação ocorre majoritariamente por meio dos estágios supervisionados (ou práticas de ensino) das licenciaturas, construindo-se diferentes tipos de parcerias entre escolas e universidades (FOERSTE, 2005).

Por um lado, o papel do estágio supervisionado na formação inicial docente é bastante problematizado e estudado, apresentado em estudos como os de Almeida e Pimenta (2014), Garcia e Higa (2016), Lima (1995, 2008, 2012), e Pimenta e Lima (2011). Por outro lado, estudos sobre a sua potencialidade para a formação dos professores supervisores (aqueles que acompanham, orientam e formam os estagiários em suas atividades nas escolas) ainda são incipientes. Uma revisão de literatura realizada sobre estágio supervisionado (MELLO, 2015) apontou a escassez de estudos a respeito da repercussão do estágio supervisionado na formação do professor supervisor: dos 52 trabalhos analisados, apenas três se ocupavam do tema.

Entende-se aqui a formação como um processo de Desenvolvimento Profissional Docente (DPD), não sendo restrita ao momento de formação inicial ou de formação continuada, abrangendo inclusive momentos de sua escolarização, ainda como alunos. Para Day (2005), o DPD relaciona-se tanto com a fase de carreira do professor, com suas aspirações como docente, sua vida familiar, dentre outros fatores pessoais, quanto com aspectos sociais e políticos, como a direção escolar, o estímulo no seu ambiente de trabalho à sua aprendizagem, os colegas professores, os alunos, as políticas públicas educacionais, entre outros, o que configura uma rede complexa de aprendizagem docente. Para este autor, o DPD tem a função de capacitar o professor a exercer a sua atividade docente, e, portanto, seu local de atuação, a escola, ocupa papel central.

Assim, a partir da visão da formação docente como DPD, considera-se o estágio supervisionado como um dos momentos em que o professor supervisor, por meio da socialização com seus pares, inclusive com os estagiários, investe em seu desenvolvimento profissional. Nesse sentido, por entender a relevância do estágio supervisionado na formação inicial de professores e acreditar na sua potencialidade para o desenvolvimento profissional dos professores em serviço, estudaram-se as contribuições do estágio para o DPD de professores supervisores de estagiários da licenciatura em Ciências Biológicas (MELLO, 2015; MELLO; HIGA, 2016, 2017a, 2017b).

Partindo dos aspectos de DPD já explicitados nessas pesquisas anteriormente realizadas, neste artigo objetiva-se compreender a influência que a busca por determinados capitais pelos professores (BOURDIEU, 1989, 2015), no intuito de se diferenciarem no campo da escola e na relação com o campo da universidade, tem em seu DPD durante a supervisão de estágio.

\section{Estágio supervisionado: alvo de interesses e disputas}

Adota-se a teoria de Bourdieu a respeito do campo como espaço social e das movimentações dos agentes nesse espaço, pois entende-se a escola e a universidade como campos 
Busca por capitais no campo da escola e sua relação ...

sociais (GENOVESE, 2014). Tal conceito é desenvolvido por Bourdieu (1983a) a fim de analisar a organização do espaço social de sociedades complexas. Segundo o autor, nessas sociedades os grupos sociais vão se tornando cada vez mais autônomos uns em relação aos outros e em relação ao macrocosmo social, criando um funcionamento interno específico. Entretanto, ao mesmo tempo em que os campos vão construindo sua autonomia em relação ao macrocosmo social, são por ele influenciados.

Nesse sentido, os diferentes campos desenvolvem regras e disputas específicas ao longo do tempo. Essas disputas são por capitais ou bens simbólicos entre os agentes de um mesmo campo ou de campos diferentes. Consequentemente, a disputa por capitais confere diferentes posições para os agentes nos campos (BOURDIEU, 1983a). Esses capitais podem ser de ordem social, cultural e/ou simbólica. Para Bourdieu (2015, p. 75), o capital social

[...] é o conjunto de recursos atuais ou potenciais que estão ligados à posse de uma rede durável de relações mais ou menos institucionalizas de interconhecimento e de inter-reconhecimento [...]. O volume do capital social que um agente individual possui depende então da extensão da rede de relações que ele pode efetivamente mobilizar e do volume do capital (econômico, cultural, simbólico) que é posse exclusiva de cada um daqueles a quem está ligado.

O capital cultural, por sua vez, pode existir em três formas:

no estado incorporado, ou seja, sob a forma de disposições duráveis do organismo; no estado objetivado, sob a forma de bens culturais - quadros, livros, dicionários, instrumentos, máquinas [...]; e, enfim, no estado institucionalizado, forma de objetivação [sob a forma de diploma escolar, por exemplo] (BOURDIEU, 2015, p. 82, grifos do autor).

Por último, o capital simbólico, segundo Bourdieu (1989, p. 134-135) é “[...] geralmente chamado prestígio, fama, etc. [...] é a forma percebida e reconhecida como legítima das diferentes espécies de capital". Enquanto a relação entre os campos é caracterizada por uma autonomia relativa entre os mesmos, medida pela sua capacidade de refração ou de modificação das demandas colocadas por outros campos (BOURDIEU, 2004). Na análise aqui proposta, inspirada por Genovese (2014), considerou-se tanto a universidade quanto a escola como subcampos do campo educacional. Assim, o estágio supervisionado pode ser considerado como uma demanda proposta pelo campo da universidade para a escola, sendo um elemento significativo na relação entre os dois.

Já o conceito de campo se faz importante na compreensão a respeito dos interesses, estratégias e disputas por capitais pelos professores no interior do campo da escola e na relação com o campo da universidade, por meio do estágio supervisionado. Acredita-se, assim, que esses interesses, estratégias e disputas influenciem o DPD promovido pela atividade de supervisão de estágio. Genovese, Queiroz e Castilho (2015) destacam essas disputas por capital em 
uma investigação sobre a incorporação, pelo estagiário, de características do habitus $^{3}$ docente do professor supervisor em um estágio colaborativo entre universidade e escola na licenciatura em Física. Para os autores, o campo escolar está manifesto “[...] na distribuição e hierarquização dos professores, ou seja, nas suas posições no interior de uma dada escola [...]” (GENOVESE; QUEIROZ; CASTILHO, 2015, p. 313), posições estas configuradas a partir de uma distribuição desigual de capital docente dentro do campo, sendo o capital docente a junção entre capital cultural escolar e capital social.

No que diz respeito ao acúmulo de capital social pelo professor supervisor investigado pelos autores, as atividades práticas desenvolvidas no estágio colaborativo de Física foram utilizadas pelo professor supervisor como possibilidade “[...] de avançar no reconhecimento do ensino prático da Física” (GENOVESE; QUEIROZ; CASTILHO, 2015, p. 319) na escola. O professor supervisor também utilizou seu capital social em relação à universidade para obter o apoio da instituição no desenvolvimento de atividades práticas e, ao mesmo tempo, acumular capital social na escola. Além disso, ainda que de forma não intencional ou planejada, o professor supervisor utilizou de seu reconhecimento pela universidade, por estar envolvido com o estágio colaborativo e com o desenvolvimento do laboratório de Física da escola, candidatando-se à direção da escola e destacando-se entre os demais professores. Os autores identificaram ainda uma disputa por capital cultural entre os professores na concorrência pelo uso de materiais e recursos didático-pedagógicos, como o laboratório de Ciências no caso da situação analisada.

Nesse sentido, é importante reconhecer que os professores supervisores de estágio e a escola podem ter interesses ao desenvolver o estágio supervisionado, mas não significa que são movidos por intenções planejadas, claras e evidentes para eles mesmos, pois estão incorporadas nos seus habitus, que em grande medida guiam suas ações dentro do campo.

Com essas questões como pano de fundo, neste trabalho estudaram-se as implicações que estas movimentações dos professores supervisores de estagiários em busca de determinados capitais têm no DPD destes agentes.

\section{Aspectos metodológicos da investigação}

A pesquisa foi desenvolvida junto a cinco professores que eram ou haviam sido recentemente supervisores de estagiários do curso de Licenciatura em Ciências Biológicas de uma universidade pública. O objetivo da investigação realizada entre os anos de 2014 e 2015 foi compreender as possibilidades de DPD para professores da Educação Básica mediante a supervisão de estagiários da licenciatura em Ciências Biológicas (MELLO, 2015).

Os professores trabalhavam em escolas estaduais e estavam em diferentes fases de carreira.

\footnotetext{
${ }^{3} \mathrm{O}$ babitus é uma estrutura estruturada por ser fruto da trajetória do indivíduo e de suas relações com as diferentes instituições socializadoras, sendo predisposto a funcionar como uma estrutura estruturante, de acordo com as práticas que determinado campo estimula (BOURDIEU, 1983b). Dessa forma, o habitus é o parâmetro para as práticas possíveis para aquele indivíduo dentro do campo, de acordo com sua origem de classe ou grupo.
} 
Busca por capitais no campo da escola e sua relação ...

Inicialmente foram realizadas observações junto a dois supervisores durante um período de quatro meses, quando se percebeu sua relação no interior do campo da escola e com o campo da universidade. Após esta fase, realizaram-se entrevistas semiestruturadas com cinco professores, incluindo esses dois. Neste texto, os resultados foram constituídos principalmente a partir das entrevistas. Os nomes dos professores são pseudônimos criados a fim de resguardar suas identidades.

Baseando-se em Day (2005) ${ }^{4}$ foram identificadas possibilidades diversas de DPD: aspectos materiais, consciência nova, informações, conhecimentos, motivacional, ajuda no trabalho, e percepção de si. As duas últimas categorias não foram descritas por Day (2005), mas construídas na análise das entrevistas. Estes resultados foram discutidos com detalhes nos trabalhos de Mello (2015), Mello e Higa (2016, 2017a, 2017b).

Explicitando de forma breve as categorias, aspectos materiais englobam elementos de ordem material, como equipamentos de museu, de laboratório, entre outros, considerados interessantes pelos docentes porque tornam as aulas mais atrativas para os alunos. Informações, por sua vez, são informações mais atualizadas, que permitem esclarecimentos sobre determinados assuntos, se referindo mais “à aquisição de conhecimentos 'básicos' ou 'ampliados' do que a conhecimentos ou destrezas novos" (DAY, 2005, p. 179, tradução nossa). Já conhecimentos, diferentemente de informações, "referem-se a uma compreensão mais profunda dos conteúdos curriculares e da pedagogia e a reflexão crítica sobre os mesmos" (DAY, 2005, p. 179, tradução nossa), ou seja, se referem a conhecimentos novos, aprofundados, e não apenas atualizados. A consciência nova faz referência a uma mudança de percepção conceitual de pressupostos. É o caso de um professor que na supervisão de estagiários se deparou com uma concepção diferente de ser professor, transformando sua prática como tal. $\mathrm{O}$ aspecto motivacional é evidenciado por um (re)entusiasmo com a carreira docente, seja com a possibilidade de entrar em contato com conhecimentos ou mesmo na troca de percepções e de críticas positivas sobre sua atuação com os estagiários, levando a um "aumento do entusiasmo e da motivação que se deriva das atividades de formação contínua, condição prévia para o desenvolvimento do pensamento e da prática" (DAY, 2005, p. 179, tradução nossa). Em ajuda no trabalho relacionam-se os fatores que podem potencializar a aprendizagem do professor em sua atividade docente, tal como a parceria nas atividades e avaliações, que pode implicar em diminuição do esgotamento no seu cotidiano e, consequentemente, permitir maior contato com seus alunos, potencializando sua aprendizagem com os mesmos. Finalmente, em percepção de si evidencia-se que com a supervisão de estagiários, os professores podem perceber sua trajetória na carreira, avaliando-a, repensando-a, podendo, inclusive, modificá-la - essa possibilidade de refletir sobre sua carreira também foi estudada por Galindo (2012) na formação do supervisor de estágio.

Assim, esses resultados das pesquisas anteriores serviram de ponto de partida para a discussão desenvolvida neste trabalho, qual seja: a relação entre a busca por capitais no interior do campo da escola ou entre o campo da universidade por parte de professores supervisores de estágio, e seu DPD.

${ }^{4}$ Day (2005) baseia-se em estudos de Kinder, Harland e Wooten (1991 apud DAY, 2005) e Harland e Kinder (1997 apud DAY, 2005) sobre o impacto de atividades de formação continuada sobre a prática de professores. 


\section{Resultados: relações no campo e entre campos e possibilidades de DPD}

Entender a diversidade e, ao mesmo tempo, as especificidades nas trajetórias de cada professor colaborador da investigação se faz importante para compreender seus interesses, suas escolhas e procura por reconhecimento (SETTON, 2015) na carreira e suas consequências no manejo de seu próprio DPD.

Compreender quais são os capitais buscados pelos professores na sua atual fase de carreira e em relação ao campo no qual se inserem, pode esclarecer seu envolvimento na supervisão de estagiários e seu consequente DPD.

Nesse sentido, serão feitas algumas aproximações de elementos da trajetória pessoal e da relação com a escola e com a universidade que permitem perceber os capitais que cada professor aparentemente procura e o seu DPD na supervisão de estagiários.

Na sequência serão apresentados e discutidos os resultados com cada professor colaborador, ressaltando-se aqueles aspectos de DPD na supervisão de estagiários que se relacionam mais evidentemente com sua busca por determinados capitais dentro da escola ou na relação com a universidade.

\section{Augusto: mobilizações por capital social e cultural junto à universidade e à escola}

Antes de ser professor, Augusto trabalhou como "boia fria", office boy e catador de papel. Ele afirma sempre ter sonhado em ser professor, e que isso começou a se tornar palpável quando a diretora de uma faculdade particular, na qual trabalhava como office boy, the ofertou o ingresso em um curso à sua escolha. Depois de graduado em Física e Matemática nessa faculdade, passou a trabalhar com administração de empresas. Como professor, trabalhou inicialmente na rede pública com contrato temporário e ao mesmo tempo na rede privada de ensino. Posteriormente, prestou concurso para o Quadro Permanente do Magistério (QPM) do Estado em Física e em Matemática, assumindo os dois cargos. Ele é mestre em Ensino de Ciências e Matemática e em 2014 tinha 12 anos de carreira docente e tem experiência de mais de 10 anos como supervisor de estagiários da licenciatura em Física, Matemática e Ciências e também experiência de pelo menos cinco anos como professor supervisor do Programa de Bolsas de Iniciação à Docência (PIBID) na escola.

Foi possível perceber os seguintes elementos que caracterizam o DPD de Augusto durante a supervisão de estágio: conhecimentos; informações; consciência nova; motivacionais; aspectos materiais e ajuda no trabalho.

Ao longo de sua atuação como formador de professores no estágio e no PIBID, Augusto acumulou capital social e reconhecimento (SETTON, 2015) por parte da universidade. Infere-se que ele utilize esse reconhecimento e capital social acumulado nas suas relações com a escola, como na resolução de situações de conflito em relação ao estágio na escola, por exemplo, e na obtenção de recursos para a realização das atividades dos estagiários na escola, como ônibus para saída de campo.

Ao se analisar o capital cultural possibilitado pela supervisão de estagiários, podemos elencar que alguns elementos de seu DPD enriquecidos pela atividade se relacionam a esse 
Busca por capitais no campo da escola e sua relação ...

tipo de capital ou permitem sua incorporação, como é o caso dos aspectos conhecimentos ou informações com o qual o professor entra em contato por meio dos estagiários:

Os alunos da universidade têm contato com as melhores pesquisas, os melhores pesquisadores, pesquisa de ponta. Eles simplesmente vão pegar essa experiência de lá, que eles têm, e vão transferir, trazer pra cá dentro de sala de aula. Olha como isso é rico! [Augusto, 2014].

Essa "transferência de experiências" da universidade para a escola implica, segundo o professor, na sua aprendizagem. Essa aprendizagem significa DPD e também acúmulo de capital cultural na forma incorporada (BOURDIEU, 2015), pois o longo tempo no qual o professor Augusto atua como professor supervisor de estágio lhe permitiu esse acúmulo. Ele ressalta, ainda, que supervisionar estagiários fez com que saísse da sua "zona de conforto", pois as aulas diferenciadas desenvolvidas nos laboratórios e nas saídas de campo com caráter investigativo e a possibilidade de ajuda no seu trabalho com relação à organização da turma, aparentemente foi tão novo e tão transformador que fez com que mudasse sua atuação frente ao ensino, à sala de aula e à escola.

Inspirado pelo caráter "diferenciado" do estágio e do PIBID, Augusto procurou fazer o mestrado, o que está em sintonia com sua procura por uma mudança na sua atividade docente e com sua busca, ao longo de sua trajetória pessoal mais recente, pela educação formal (CHANTRAINE-DEMAILLY, 1995) e, por meio dela, a possibilidades de ascensão social.

A possibilidade de cursar o mestrado, segundo o professor, foi se evidenciando quando começou a ser supervisor de estagiários e do PIBID e passou a fazer contato com professores da universidade. Assim, percebe-se que ele foi acumulando um capital social na sua relação com o campo da universidade, que lhe possibilitou, por outro lado, investir no acúmulo de capital cultural incorporado e institucionalizado (BOURDIEU, 2015) por meio do mestrado.

Portanto, para o professor Augusto a supervisão de estágio ao longo de sua carreira profissional lhe possibilitou um acúmulo de capital social no campo da escola e na relação com o campo da universidade, permitindo que usasse desse reconhecimento para amenizar situações de conflito na escola e também para se motivar a se candidatar ao mestrado. Ao mesmo tempo, os aspectos de DPD impulsionados pelo estágio significaram tanto direta quanto indiretamente um acúmulo de capital cultural incorporado e institucionalizado.

\section{Bia: mobilizações por capital social e simbólico junto aos alunos}

Bia não tinha a intenção de ser professora ao ingressar na faculdade, e sim, tornar-se bióloga marinha. Entretanto, ao longo do curso, essa possibilidade foi se tornando distante por questões financeiras. Durante o curso, em uma faculdade particular, ela teve apoio financeiro dos pais e também trabalhou como vendedora informal de roupas e, ao final do curso, como bancária. Durante seu estágio supervisionado, a possibilidade de ser professora lhe pareceu mais viável, o que a levou a concluir a Licenciatura e não o Bacharelado em Ciências Biológicas. Concluída sua graduação, trabalhou como professora com contratos temporários. Até o ano de 2014, trabalhava em duas escolas por meio desse tipo de contrato, não tendo prestado concurso, mesmo sendo professora há 6 anos. Ela tem três especializações: uma na área ambiental, uma em Artes e outra em Educação Especial. 
A relação com os alunos parece ser um elemento de preocupação para Bia, que destaca o contexto social deles: muitos de famílias envolvidas em situações vulneráveis, como o uso de drogas. Assim, ela percebe a necessidade afetiva de seus alunos e procura estabelecer com eles um vínculo nesse sentido. Ao falar a respeito de seu início de carreira, ela destaca o fato de aprender com professores colegas de trabalho sobre como lidar com as turmas, como ser respeitada e, ao mesmo tempo, estabelecer uma relação de confiança com os alunos.

Assim, percebe-se que a professora tem uma grande preocupação em acumular capital social com os alunos, estabelecer uma ligação com eles por meio de brincadeiras ou conversando sobre seus problemas pessoais. Esse capital social, aparentemente, é importante para que a professora consiga manejar a indisciplina de suas turmas, pois é estabelecida uma relação de carinho e de respeito. Nesse ponto, estabelece-se também uma relação com os alunos para a qual é necessário um acúmulo de capital simbólico, o qual implica em um reconhecimento de autoridade e diferenciação da professora pelos alunos. Além desse aspecto, também foi visível o seu investimento em recursos didáticos e do conteúdo da disciplina, pois ela diz se preocupar em separar materiais para as suas aulas, assim como vídeos, reportagens e filmes, para atrair a atenção da turma e desenvolver o conteúdo curricular da disciplina.

Em estudos sobre o ciclo de vida dos professores e suas preocupações principais em cada fase de vida, Sikes (1985 apud GARCIA, 1999, p. 62) afirma ser importante na primeira etapa de ciclo vital dos professores, compreendida na faixa etária entre os 21 e 28 anos, na qual se insere Bia, aprender a lidar com a indisciplina dos alunos e a dominar o conteúdo da disciplina.

Ademais, ela tem interesse em continuar estudando, fez vários cursos de especialização e participa de cursos que a universidade oferece na área biológica, que provavelmente, são relevantes para a sua atividade de ensino porque oferecem formas de trabalhar com os conteúdos, e o aprofundamento nos mesmos.

Dessa forma, para a professora Bia, obter capital social e simbólico com os alunos é primordial na fase em que se encontra. Nesse sentido, o DPD durante o estágio para Bia parece girar em torno desse interesse, sendo possível observar os seguintes elementos: ajuda no trabalho, motivacional, materiais e aspectos informacionais.

As atividades que as estagiárias desenvolvem em suas turmas ou os materiais com os quais elas trabalham e as informações que trazem da universidade, chamam a atenção de Bia para a possível repercussão entre os alunos, sua aprendizagem e seu envolvimento com a disciplina. É um vínculo que a professora procura estabelecer com os alunos, marcado fortemente pela preocupação com a aprendizagem deles.

[...] o que en achei legal de ter as estagiárias, e que é diferente, é isso, éporque elas ajudam muito mesmo. Quando você acha, assim, estagiário certo, eu falo (risos), você acaba tendo o beneficio muito bom. Porque você tem aulas diferenciadas, às vezes materiais que têm na universidade, eles acabam pegando emprestado e trazendo o que é diferente para os alunos, que a gente não tem, às vezes no laboratório. Igual, semana passada, elas trouxeram várias espécimes de cnidários e poriferos, né? E foi bem bacana, os alunos adoraram. Adoraram, eles ficaram bem até, como vou dizer, eles participam muito e acabam ficando agitados. Mas a experiência boa épor isso [Bia, 2014, grifos nossos]. 
Dessa forma, até a maneira como ela organiza e se envolve no estágio converge para seu objetivo como professora, e sua busca por esses determinados capitais, o social e simbólico junto a seus alunos (lembrando que essa busca não é, necessariamente, voluntária ou consciente, segundo Bourdieu) naquele determinado momento. Nesse sentido, Bia prefere grupos menores de estagiários, segundo ela, para não dispersar a atenção dos alunos. Assim, por sugestão da professora da universidade, orientadora do estágio, dividiu a sua turma de alunos em dois grupos. Enquanto um dos grupos fica em sala de aula com aulas "teóricas" junto à professora Bia, o outro fica com as estagiárias em aulas "práticas" no laboratório de Ciências. A professora sempre procura acompanhar um pouco a aula das estagiárias, segundo ela relata, pelo menos para averiguar o comportamento dos alunos, reforçando sua preocupação com a indisciplina.

Portanto, para Bia, a supervisão de estagiários possibilitou, mesmo que de forma não evidente para ela própria, alguns aspectos de DPD que se relacionam com seus objetivos e busca por capital social e simbólico junto aos seus alunos na fase de carreira docente em que se encontra, sem deixar de levar em consideração a aprendizagem dos mesmos.

\section{Clarice: mobilizações por capital cultural}

Clarice cursou tanto o bacharelado quanto a licenciatura em Ciências Biológicas em uma universidade pública. Afirma que a docência é uma consequência de sua formação como bióloga. Com essa afirmação poderíamos concluir que a professora não se identifica com a carreira docente; entretanto, ela afirma gostar de ser professora e mesmo enquanto estava cursando a graduação já atuava na profissão, em regime de contrato temporário. A professora tem mestrado em Botânica e doutorado em Agronomia e durante sua pós-graduação também trabalhou como professora com contrato temporário. Ao terminar o doutorado, foi nomeada professora de Biologia no concurso do Estado, trabalhando como professora do QPM há 10 anos. Ela trabalha 20 horas em duas escolas e diz que não tem necessidade de trabalhar 40 horas semanais, visto que, na parceria com o marido, é possível manter financeiramente a família. Assim, a professora diz que tem tempo para se dedicar aos estudos e à família.

Percebe-se a centralidade dos estudos na sua carreira, ou seja, a importância que a professora atribui ao acúmulo de capital cultural dentro da área de conhecimento da Biologia. Ela afirma, inclusive, que a escolha por lecionar a disciplina de Biologia no Ensino Médio - e não a de Ciências no Ensino Fundamental - baseou-se na possibilidade de aprofundar o seu próprio conhecimento, como professora da disciplina. Outra estratégia que lhe possibilita acúmulo de capital cultural é que, tendo em vista que não trabalha em jornada de 40 horas semanais, é possível dedicar tempo para seus estudos. Considerando-se que o tempo é um elemento importante e, muitas vezes, limitante na carreira docente, essa estratégia lhe confere maior possibilidade de acúmulo de capital cultural, se comparado com professores que trabalham com uma jornada semanal de 40 horas em diferentes escolas.

Por ter circulado com frequência no campo da universidade (graduação, mestrado e doutorado), presume-se que Clarice obteve um capital social nas relações estabelecidas com a universidade. Isso lhe possibilita estar informada sobre cursos que a instituição oferece, podendo frequentá-los e, inclusive, desejando cursar um pós-doutorado.

Clarice relata que, mesmo sem estagiários, procura inovar em suas aulas, e que a supervisão de estagiários é interessante por propiciar a troca de informações, além também da pos- 
sibilidade dos estagiários trazerem materiais diferentes da universidade, assim como aplicativos para celular que podem ser usados em sala de aula, e até mesmo algum olhar diferente para o conteúdo, oportunizando para a professora uma consciência nova sobre o assunto. Esses são aspectos que se relacionam com o interesse da professora em acumular capital cultural na sua disciplina de atuação, oportunizados pela supervisão de estagiários.

No momento que você está conversando com alguém, você já está trocando informação e isso é muito rico. A Biologia é muito ampla, a gente não sabe de tudo. Então pontualmente, às vezes, ela te passa uma informação, aqui ou ali que você não tinha feito o link, ainda uma forma de ver diferente. Isso é legal. Então eu acho que contribui sim, com relação ao conteúdo, alguma coisinha. [Clarice, 2014].

Assim, observa-se também o sentido de Ajuda no Trabalho como possibilidade de DPD para Clarice, e que este também envolve uma busca por capital cultural na sua profissão, procurando aprender com os estagiários assuntos que não conhecia, assim como maneiras de trabalhar esses assuntos.

\section{Denise: mobilização por capital cultural na relação com a universidade}

Denise ingressou no curso de Ciências Biológicas em uma universidade pública com a intenção de solicitar transferência para Medicina. Entretanto, não solicitou a transferência por ter se identificado com a área ambiental do curso. Sem a inclinação para ser professora quando deu início aos seus estudos, segundo ela, se formou em Licenciatura, além do Bacharelado, apenas para aproveitar a oferta das duas modalidades pela universidade. Depois de graduada, trabalhou como pesquisadora na área ambiental em um Estado distante e, ao voltar para o Estado no qual reside atualmente, trabalhou como professora em regime temporário. Ao longo de sua carreira, trabalhou em diferentes escolas, já compondo o QPM do Estado com as disciplinas de Biologia e Matemática para o Ensino Médio e para a Educação de Jovens e Adultos.

Denise possui algumas especializações na área ambiental e também realizou, recentemente, o Programa de Desenvolvimento Educacional, um projeto de formação continuada do Estado em parceria com uma universidade pública. Além disso, participa de diferentes cursos, minicursos e palestras ofertados por essa universidade, indicando seu interesse no acúmulo de capital cultural.

Durante sua carreira de 27 anos como docente, recebeu estagiários de diferentes áreas: Biologia, Ciências, Artes, Filosofia, entre outros cursos, com os quais, comenta, estabeleceu muitas trocas. Ela afirma ter aprendido com eles novas maneiras de abordar a sua disciplina em sala de aula, ter entrado em contato com tópicos mais recentes na área da Biologia (conhecimentos) e aprendido assuntos novos com estagiários de outras áreas (consciência nova). Além disso, os estagiários trazem materiais da universidade aos quais ela não teria acesso (aspectos materiais). Também foi observado o desenvolvimento de aspectos de ordem motivacional. Percebeu-se que, assim como a professora Clarice, Denise tem um grande interesse em acumular capital cultural incorporado ou institucionalizado (BOURDIEU, 2015), o que marca o seu DPD na relação com os estagiários.

Entretanto, Clarice tem uma postura mais individual na sua busca pelo DPD, priorizando-o na forma escolar, ou seja, por meio de titulação, cursos, entre outros (CHANTRAINE- 
Busca por capitais no campo da escola e sua relação ...

DEMAILLY, 1995), ou, segundo Bourdieu (2015), na forma de capital cultural institucionalizado. Denise, por sua vez, atribui um valor de aprendizagem à relação estabelecida com o estagiário, o que não exclui sua busca individual pelo DPD na forma escolar e de capital cultural institucionalizado. Contudo, chama a atenção a postura de aprendiz que Denise assume na supervisão de estagiários. Essa postura está presente tanto na relação com a universidade por meio dos discentes que ela recebe quanto por meio dos cursos que frequenta.

Assim, destaca-se essa mobilização de Denise em obter ou acumular capital cultural mediada pela relação com a universidade.

Eu acho que a escola tem que abrir portas, e esse aluno que está na universidade, em muitas áreas, ele vai te trazer informaģões. Então eu acho que esse vinculo não pode perder. Por exemplo, se você está lá, vamos pegar uma coisa que mudou muito, a genética, vamos supor. À galope. Por mais que eu leia, é diferente de você que está lá. Então esse aluno que vem, com certeza ele vai complementar muitas coisas. Então esse intercâmbio não pode morrer. Você precisa vir conhecer a realidade, onde futuramente você vai atuar, né? E as informacõoes mais novas, a, como eu falo, a evolucão, os novos conhecimentos mesmo, é a universidade que está te trazendo hoje. E que eu posso estar defasada, por mais que eu pretenda acompanbar, eu não vou acompanhar todas áreas. Há um leque que você abre dentro da Biologia, só dentro da Biologia. [Denise, 2014].

Deste modo, Denise, na sua relação com os estagiários, interessa-se por acumular capital cultural por meio do contato com abordagens diferentes de conteúdo, autores que eles utilizam e materiais diferentes trazidos para o uso em sala de aula.

\section{Érico: mobilização por capital social e simbólico com os alunos}

O professor Érico é graduado em Licenciatura e Bacharelado em Ciências Biológicas por uma universidade da rede privada. Durante a graduação trabalhou como professor em cursos pré-vestibulares e supletivos. Depois de graduado, trabalhou em laboratórios de análises químicas e biológicas, com "salários bons", segundo suas palavras, mas com uma rotina de trabalho que não o satisfazia. Numa determinada época de sua vida, fez um concurso para o QPM do Estado e assumiu o cargo de professor, no qual, segundo ele, se sente realizado. Ele ressalta que não teve a oportunidade de fazer pós-graduação, pois teve que sustentar sua família desde recém-formado.

Érico é responsável pelas aulas de Ciências no Ensino Fundamental, tanto regular quanto na Educação de Jovens e Adultos, com uma jornada de trabalho de 40 horas nesta única escola. Durante sua carreira, recebeu estagiários de Biologia, Química e Física.

Desenvolveu grande parte de sua carreira (15 dos 27 anos de docência) na escola onde trabalhava na época do desenvolvimento desta investigação e se envolveu muito com o ambiente escolar, o que lhe permitiu um acúmulo de capital social na escola. Um exemplo disso é o seu relato a respeito da revitalização da escola feita por ele e demais professores, revertendo o processo de decadência estrutural e pedagógica pela qual a mesma vinha passando. Essa revitalização não foi apenas com relação à estrutura física, mas na produção de conhecimento, como por exemplo, a proposta do Projeto de Iniciação Científica (PIC), um projeto de investigação da 
escola. Outro fato que permite inferir que possui um alto capital social no ambiente é o pedido, por parte de outros professores, que Érico se candidatasse à sua direção, o que ele recusou.

A sua preocupação enquanto professor, percebida na análise de sua entrevista, é com a interação com seus alunos, tanto nos aspectos de normatização e disciplina, quanto de perceber suas dificuldades pessoais. Além disso, se dedica a desenvolver boas aulas, divertidas, motivadoras, mas sem perder o objetivo do ensino de conteúdo. Ou seja, o professor parece ter um grande interesse em acumular capital social e também simbólico (autoridade) junto aos alunos.

Atentando ao tipo de capital que o professor busca, o seu DPD na relação com os estagiários envolve aprender atividades que lhe proporcionem essa aproximação maior com os estudantes, como por exemplo, aulas práticas que os estagiários fizeram e que chamaram a atenção deles, não tanto pelo conteúdo em si, mas pela impressão que causou nos mesmos. Além disso, solicita que os estagiários façam visitas guiadas a museus, também uma forma de atrair os estudantes:

Eu lembro desse cara ai de Quimica e o outro estagiário que foram dois caras que trouxeram práticas para mim que eu usei dentro de sala de aula durante um bom tempo. Esse Tromba de Elefante [nome do experimento] aí eu não tinha a menor ideia de como que fażia. E eu vi o cara fažendo, os alunos piraram e eu falei: Ó, deixa a receita pra mim aí. Deve estar lá no laboratório, se estiver, a receita lá. Já usei muitas vezes. [Érico, 2014, grifos nossos].

É possível interpretar que o professor considera interessante o experimento proposto pelo estagiário porque os alunos ficaram interessados. Dessa forma, passa a incorporá-lo nas suas aulas práticas como forma de motivar os alunos. No momento de orientação dos estagiários, de acordo com seu relato, também se percebe essa preocupação com os estudantes de forma central no seu profissionalismo e identidade docente, buscando passar essa preocupação para os alunos da universidade.

No caso do professor Érico, o DPD, guiado pela busca de capital social e simbólico frente aos alunos, foi em grande parte de aspectos materiais e ajuda no trabalho. Ademais, ele constrói, na supervisão dos estagiários, uma percepção de si como professor, tanto na sua trajetória de formação quanto na sua atuação presente.

A escola onde trabalha, aparentemente, possui iniciativas que se aproximam de uma cultura de trabalho colaborativo (DAY, 2005) com o desenvolvimento de um projeto transdisciplinar que envolve todos os professores e estudantes em atividades investigativas e de divulgação de conhecimento dentro da própria escola, como o PIC, referido anteriormente. Além disso, a coordenação pedagógica, segundo Érico, avalia o projeto de estágio elaborado pelo estagiário, analisando sua adequação ao planejamento do professor e às condições da escola, o que sugere também uma relação mais colaborativa de trabalho na escola.

Nesse sentido, talvez por estar envolvido em práticas de DPD da própria instituição escolar, o professor Érico não as procure fora da escola ou em relações que não sejam com seus colegas e alunos. Assim, o que objetiva e ocorre no estágio está mais relacionado ao desenvolvimento profissional dos estagiários do que com o seu próprio. $\mathrm{O}$ estágio tem consequências indiretas em seu DPD, como nos aspectos materiais e na ajuda no trabalho, como já mencionado, estimulando-o com maneiras diferentes de obter uma maior interação com os alunos, propiciando-lhe acúmulo em capital social. 


\section{Análise: as movimentações por capitais, a produção de conhecimento como dominação simbólica entre os campos e possibilidades de DPD}

A supervisão de estágio por professores de Ciências e Biologia lhes possibilita algum tipo de DPD, como se percebeu ao longo de nossa discussão. Ao mesmo tempo, essa atividade está inserida na lógica interna do campo da escola, na disputa por capitais pelos professores, assim como na relação entre o campo da escola e da universidade. Dessa maneira, a busca por determinados capitais pelos docentes parece ter consequências no DPD durante a supervisão de estágios, como se evidenciou nesta investigação.

Bia e Érico movimentavam-se no campo da escola naquele momento para acúmulo de capital social e simbólico junto a seus alunos, assim as atividades dos estagiários lhes despertaram interesses por propiciar essa aproximação com seus alunos. Clarice, Denise e Augusto, por sua vez, e com especificidades próprias, buscam capital cultural na relação com o campo da universidade ou por meio da socialização com os estudantes dela. Porém, Augusto apresenta a especificidade da busca pelo capital social na relação com a universidade, além do cultural.

Assim, esse tipo de análise permite-nos atentar para a complexidade das relações estabelecidas durante o estágio supervisionado e que englobam o DPD do professor supervisor, uma vez que essa busca por capitais sinaliza as relações de poder internas no campo da escola e entre os campos da escola e da universidade. Ademais, a relação com o conhecimento produzido pelos dois campos, o que pode significar DPD para o professor, é, ao mesmo tempo, um indício do poder simbólico entre os campos.

A relação entre o campo da escola e o campo da universidade é uma relação de poder simbólico (GENOVESE, 2014), assim, há diferença hierárquica entre professor da escola e professor da universidade, apesar de todos serem professores. Há diferenças de salário, de carreira, de tipo de trabalho, de envolvimento com atividades de pesquisa, de valorização social (GARCIA, 2012). E toda essa diferenciação simbólica esconde diferenciações sociais e legitima a dominação de um campo sobre o outro.

Nesse sentido, uma decorrência desse tipo de dominação é a valorização diferenciada que a produção de conhecimento de um tem sobre a de outro. Assim, quando se analisou a relação estabelecida por Augusto e Denise com o conhecimento produzido pela universidade, percebe-se uma valorização do capital cultural produzido pela universidade, em detrimento do seu próprio capital cultural.

Denise se julga defasada com relação a alguns conhecimentos, esperando que os estagiários os complementem com a produção realizada pela universidade. Para ela, são capitais culturais diferentes, atribuindo à universidade a pesquisa e à escola a "realidade" da educação: "Então aí comprova mais uma vez: elesprecisam dessa realidade? Precisam. E nós precisamos dessa pesquisa, né? Não estamos fazendo isso. Tem alguém fazendo? Que bom, vamos lá ver. Vamos lá escutar". [Denise, 2014].

Augusto também julga que a pesquisa e o conhecimento são produzidos pela universidade, à escola reserva-se a sua aplicação no ensino:

Os alunos da universidade federal têm contato com as melhores pesquisas, os melhores pesquisadores, pesquisa de ponta, eles simplesmente vão pegar essa experiência de lá, que eles tem, e eles vão transferir, trazer pra cá dentro de sala de aula. [Augusto, 2014]. 
Há uma crença compartilhada, em geral, pelos professores da escola que legitima a universidade como produtora de conhecimentos mais atuais, mais científicos e legítimos (BOURDIEU, 1989). Dessa forma, os professores da escola - e a sociedade como um todo - reforçam o poder que a universidade tem sobre a produção de conhecimento da escola.

A valoração distinta que se dá aos tipos de capitais produzidos pelos campos, evidenciado neste trabalho, constitui importante preocupação. A escola é refém de uma visão tecnicista de sua função e do que seja educar, enquanto que a universidade, apesar de ser refém dessa mesma visão, ainda tem reservada a propriedade sobre a atividade de pesquisa, o que lhe confere uma maior valoração e legitimação (GARCIA, 2012).

Caso se mantenha e se reforce a relação entre os campos dentro desta perspectiva, a autonomia do campo da escola em relação à universidade continuará sendo restrita (GENOVESE, 2014), uma vez que há, por parte da primeira, uma grande absorção das demandas postas pela segunda, e mesmo de seu capital cultural, mantendo uma realidade de dominação. Desta forma, a autonomia profissional do professor da Educação Básica é mínima, por depender da geração de conhecimento de outro agente que não ele próprio restando ao ensino o que foi produzido por outros. (CONTRERAS, 2012).

Espera-se que, ao evidenciar as formas de poder simbólico entre universidade e escola, seja possível perceber que muitas ações da universidade podem ser "colonizadoras" de práticas das escolas (FIORENTINI, 2010), e que isso permita propor novas relações, favorecendo assim, durante o estágio supervisionado, o DPD não só dos futuros professores, mas também dos professores em serviço ao supervisionarem os estagiários. E, quiçá, seja possível contribuir para uma valoração diferente do conhecimento produzido pelos professores da escola, reivindicando condições de carreira que evidenciem a produção de conhecimento na atuação profissional do professor da Educação Básica.

\section{Considerações finais}

Ressaltou-se com este trabalho a contribuição que o olhar sobre as instituições escolares e da universidade e seus agentes, mediado pelo conceito de campo social (BOURDIEU, 1983a, 2004) oferece para a análise de suas relações internas e entre os campos, além de permitir destacar os significados atribuídos às atividades que os agentes desempenham, como, neste caso, a supervisão de estágio.

Assim, o entendimento da escola como campo possibilita a compreensão de que os professores ocupam uma posição nesse campo de acordo com o capital que buscam acumular, e de que existem, por parte deles, interesses e disputas (GENOVEZ, 2008). Dessa forma, o sentido atribuído pelos professores da escola à supervisão parece, em grande parte, influenciado pelo tipo de capital que buscam acumular no seu campo e na relação com o campo da universidade.

Sendo assim, essa articulação de perspectivas na análise sobre o estágio supervisionado permitiu entender que o DPD durante a supervisão é consequência, ao mesmo tempo, das relações de poder internas ao campo da escola e entre os campos e dos objetivos, preocupações e interesses que os professores possuem em suas diferentes fases de carreiras.

Acredita-se que, com a tentativa de considerar as relações e interesses referidos, seja possível tornar o estágio supervisionado mais significativo para os envolvidos, como ressaltam 
Genovese, Queiroz e Castilho (2015), e reconfigurar a relação entre campos, numa perspectiva de intensificar a autonomia da escola e de seus professores, para, assim, se tentar "descolonizar" as práticas das escolas e estabelecer uma relação mais colaborativa entre universidade e escola durante o estágio supervisionado, com consequente DPD de todos os envolvidos.

\section{Referências}

ALMEIDA, M. I.; PIMENTA, S. G. Centralidade do estágio em cursos de didática nas licenciaturas: rupturas e ressignificações. In: ALMEIDA, M. I.; PIMENTA, S. G. (Org.). Estágios supervisionados na formação docente. São Paulo: Cortez, 2014. p. 15-40.

BOURDIEU, P. Algumas propriedades dos campos. In: BOURDIEU, P. Questões de sociologia. Rio de Janeiro: Marco Zero, 1983a. p. 89-94.

BOURDIEU, P. Esboço de uma teoria da prática. In: ORTIZ, R. (Org.). A sociologia de Pierre Bourdieu. São Paulo: Ática, 1983b. p. 46-81.

BOURDIEU, P. O poder simbólico. Lisboa: Difel, 1989.

BOURDIEU, P. Os três estados do capital cultural. In: NOGUEIRA, M. A.; CATANI, A. M. (Org.). Escritos de educação. Petrópolis: Vozes, 2015. p. 79-88.

BOURDIEU, P. Os usos sociais da ciência: por uma sociologia clínica do campo científico. São Paulo: Ed. Unesp, 2004.

CHANTRAINE- DEMAILLY, L. Modelos de formação contínua e estratégias de mudança. In: NÓVOA, A. (Org.). Os professores e a sua formação. 2. ed. Lisboa: Dom Quixote, 1995. p. 139-158.

CONTRERAS, J. D. A autonomia de professores. São Paulo: Cortez, 2012.

DAY, C. Formar docentes: cómo, cuándo y en qué condiciones aprende el profesorado. Madrid: Narcea, 2005.

FIORENTINI, D. Relações entre a formação docente e a pesquisa sobre os processos de conhecimento e a prática dos professores. In: HAGEMEYER, R.C.C. (Org.). Formação docente e contemporaneidade: referenciais e interfaces da pesquisa na relação universidade- escola. Curitiba: Ed. UFPR, 2010. p. 23-52.

FOERSTE, E. Parceria na formação de professores. São Paulo: Cortez, 2005.

GALINDO, M. A. O professor da escola básica e o estágio supervisionado: sentidos atribuídos e a formação inicial docente. 2012. Dissertação (Mestrado em Educação) Faculdade de Educação, Universidade de São Paulo, São Paulo, 2012. Disponível em: <http://www.teses.usp.br/teses/disponiveis/48/48134/tde-24042012-151944/pt-br.php>. 
Acesso em: 19 ago. 2017.

GARCIA, C. M. Formação de professores para uma mudança educativa. Porto: Porto Editora, 1999.

GARCIA, T. M. F. B. Ensino e pesquisa em ensino: espaços da produção docente. In: GARCIA, N. M. D et al. (Org.). A pesquisa em ensino de física e a sala de aula: articulações necessárias. São Paulo: Livraria da Física, 2012. p. 239-259.

GARCIA, T. M. F. B.; HIGA, I. Estágio e formação de professores: veredas, fronteiras, caminhos. In: LAWALL, I. T.; CLEMENT, L. (Org.). Relatos e reflexões sobre estágio curricular supervisionado: cursos de licenciatura da UDESC. Goiânia: C\&A Alfa Comunicação, 2016. p. 11-42.

GENOVESE, L. G. R. Os graus de autonomia das práticas dos professores de física: relações entre os subcampos educacionais brasileiros. In: CAMARGO, S. et al. (Org.). Controvérsias na pesquisa em ensino de física. São Paulo: Livraria da Física, 2014. p. 61-88.

GENOVESE, L. G. R.; QUEIROZ, J. R. O.; CASTILHO, D. D. Incorporação do habitus de homo magister no interior do estágio colaborativo em física: um olhar sobre a relação entre professor supervisor e estagiário. Ensino em Re-Vista, Uberlândia, v. 22, n. 2, p. 311-331, 2015. Disponível em: <https://doi.org/10.14393/ER-v22n2a2015-5>. Acesso em: 23 abr. 2018.

GENOVEZ, L. G. R. Homo magister: conhecimento e reconhecimento de uma professora de ciências pelo campo escolar. 228 f. Tese (Doutorado em Ensino de Ciências) - Faculdade de Ciências, Universidade Estadual Paulista Júlio de Mesquita Filho, Bauru, 2008. Disponível em: <https://repositorio.unesp.br/handle/11449/101999>. Acesso em: 19 ago. 2017.

LIMA, M. S. L. Estágio e aprendizagem da profissão docente. Brasília: Liber, 2012. LIMA, M. S. L. O estágio supervisionado como elemento mediador entre a formação inicial do professor e a educação continuada. 1995. 152 f. Dissertação (Mestrado em Educação) - Faculdade de Educação, Universidade Federal do Ceará, Fortaleza, 1995.

LIMA, M. S. L. Reflexões sobre o estágio / prática de ensino na formação de professores Revista Diálogo Educacional, Curitiba, v. 8, n. 23, p. 195-205, 2008. Disponível em: <http:/ /www2.pucpr.br/reol/pb/index.php/dialogo?dd1=1836\&dd99=view\&dd98=pb>. Acesso em: 23 abr. 2018.

MELLO, A. C. R. Desenvolvimento profissional de professores supervisores de estágio durante a socialização com os estagiários de ciências biológicas. 204 f. Dissertação (Mestrado em Educação) - Setor de Educação, Universidade Federal do Paraná, Curitiba, 2015. Disponível em: < http://acervodigital.ufpr.br/handle/1884/42790>. Acesso em: 1 set. 2017.

MELLO, A. C. R.; HIGA, I. Contribuições da supervisão de estágio para o desenvolvimento profissional docente de professores de ciências e biologia. Enseñanza de las Ciencias, Barcelona, n. extra, p. 2174-6486, 2017b. Disponível em: <https://ddd.uab.cat/ 
record/184106>. Acesso em: 23 abr. 2018.

MELLO, A. C. R.; HIGA, I. Pode o estágio supervisionado ser potencializador do desenvolvimento profissional de professores de ciências e biologia da educação básica? Revista da SBEnBio, Rio de Janeiro, n. 9, p. 2769-2780, 2016. Disponível em: <http:// www.sbenbio.org.br/wordpress/wp-content/uploads/renbio-9/pdfs/1987.pdf >. Acesso em: 23 abr. 2018.

MELLO, A. C. R.; HIGA, I. A supervisão de estagiários da licenciatura como possibilidade de desenvolvimento profissional docente para professores de Ciências e Biologia. In: ENCONTRO NACIONAL DE PESQUISA EM EDUCAÇÃO EM CIÊNCIAS, 11. 2017, Florianópolis. Anais... Florianópolis: Abrapec, 2017a. Disponível em: <http://www. abrapecnet.org.br/enpec/xi-enpec/anais/listaresumos.htm>. Acesso em: 23 abr. 2018.

PIMENTA, S. G. O estágio na formação de professores: unidade, teoria e prática? 7. ed. São Paulo: Cortez, 2006.

PIMENTA, S. G.; LIMA, M. S. L. Estágio e docência. 6. ed. São Paulo: Cortez, 2011.

SAVIANI, D. Formação de professores: aspectos históricos e teóricos do problema no contexto brasileiro. Revista Brasileira de Educação, Rio de janeiro, v. 14, n. 40, p. 143- 155, 2009.

SETTON, M. G. J. A escolha e o reconhecimento pela educação: o caso de Antônio.

Educação e Pesquisa, São Paulo, n. 41, p. 1405-1418, 2015. Número especial. 